\title{
Report on Five Years of Operation of a Leprosy Control Scheme in the West Nile District of Uganda
}

\author{
DR. E. H. WILLIAMS \\ Kuluva Hospital, Arua, Uganda
}

In the latter half of 1958 the West Nile District Council introduced Byc-Laws to control leprosy. Basically these were very simple, consisting of rules to compel people thought to be suffering from leprosy to attend for examination and diagnosis, and to make it compulsory for persons diagnosed as having leprosy to attend for treatment. There were also provisions to try and segregate people with the more infective forms of leprosy, termed 'contagious cases'. 'These rules being in the form of BycLaws there was of necessity a punishment inserted, namely a fine of ten shillings only. This fine has been applied on relatively few occasions.

These Byc-Laws were introduced to a background of one large leprosarium with 400 places at Kuluva, one small leprosarium at Wandi, and 3 outpatient clinics. In order to implement the Bye-Laws a Committee of local Government Medical Officers and Mission Doctors met and agreed to increase the number of outpatient clinics to all the Government Dispensaries in the West Nile. In this way an immediate potential coverage of the population to nine-tenths was effected. A uniform system of registration, examination and treatment with Dapsone of all patients was worked out. From the result of two surveys carried out by the Ieprologist of Uganda, DR. J. A. KINNEAR BROWN, it was expected that about 4,OOO patients were in the West Nile, which has a population of approximately 400,000 .

Commencing in October, I958, and thereafter three or four times a year for the full five years, every clinic was visited using transport generously supplied by UNICEF. At each visit patients under treatment have been examined in sunlight, and individual progress recorded on their cards. New patients complaining of leprosy have been examined and those with lcprosy registered for treatment. After about two years increasing numbers of patients had shown such a response to treatment that it was felt that they could be discharged. Because of the numbers of patients involved precluding too detailed an assessment of the arrest of their disease it was decided to effect Discharge in two stages. In the first instance a Temporary Discharge Certificate was issued and the patient instructed to report for re-examination in six months. If there was then no sign of relapse a Pcrmanent Discharge Certificate was issued, but patients informed that they could come for re-examination at anytime if they thought their leprosy was returning. In practice many of the patients with Temporary Discharges did not return, and have therefore been presumed to have not developed new signs of leprosy. 
$\Lambda$ the beginning there was some misunderstanding of the working of the scheme on the part of Chiefs and others, but gradually the idea of the scheme caught on, and its operation reached its zenith in the third year. Since the third year the scheme has lost a great deal of its original impetus, due to pre-occupation of the people with Independence and improved economic prospects in the District. 'There is also no doubt that like all such schemes, when the novelty palls, enthusiasm for it diminishes. Absenteeism has been the main evidence of loss of impetus, and during the fifth year this has assumed quite large proportions as compared with previous years. Chiefs have found it difficult to trace absentecs because these have moved away from their original homes and perhaps changed their names as well.

The results of the scheme can best be assessed by consideration of the following figures. The names of the Out-patient Clinics are as follows, starting from the North of the District.

Matuma, Yumbe, Koboko, Omogo, Maraca, Wandi, Rhino Camp, Mvara, Kuluva, Bondo, Logiri, Warr, Paida, Okollo, Angal, Wadelai, Pakwach and Panymur, eighteen in all.

\section{Figures}

Registered Temporary Permanent Deaths

Patients Discharges Discharges Recorded Transfers Absentees Attending Relapse Contagiouts

\begin{tabular}{llllllrrr}
\hline $\mathbf{4}, \mathbf{2 5} 8$ & $\mathbf{1}, 054$ & $36 \mathbf{1}$ & 49 & 97 & 1,103 & 2,019 & 64 & $2 \mathrm{I}$ \\
$\mathbf{1 0 0} \%$ & $25 \%$ & $\mathbf{8} \frac{1}{2} \%$ & $\mathbf{1} \%$ & $2 \%$ & $26 \frac{1}{2} \%$ & $47 \%$ & $6 \%$ & \\
& & & & & & & \multicolumn{2}{c}{ of Discharges }
\end{tabular}

COMMENTS ON FIGURES

(I) Number of patients registered. This figure is reasonably accurate and the number of patients registered twice is very few.

(2) Temporary Discharges. This figure should be taken with the rate of relapse and it will be seen that the figures tend to show that the relapse rate is low. The majority of cases discharged however, are tuberculoid in type, and some were not very active cases. It has been learned by experience that it is important to distinguish between Tuberculoid and Dimorphous cases at the time of original diagnosis. Nearly all relapses were cases originally diagnosed as Tuberculoid before proficiency had been gained in diagnosing those which were in fact Dimorphous. The impression gained is that many Tuberculoid cases need only have two years of treatment, but that although they may show clinically dramatic improvement and an absence of clinically discernible lesions in less than two years, Dimorphous Cases must have at least four years of treatment to avoid a high relapse rate.

(3) Permanent Discharges. Less than half of the cases temporarily discharged have returned for re-examination. Those that have returned for reexamination have done so because they thought they had a recurrence of leprosy. In many of these cases there were associated Onchocercal lesions which is called leprosy in the local vernaculars. 
(4) Deaths. 'This figure represents the number recorded and cannot be taken as a true figure of the number of patients who have died.

(5) Relapses. No comment other than that made under 'T'emporary Discharges.

(6) Absentees. This figure represents patients who have stopped attending for at least several months and have not been traced by the chiefs. It is difficult to surmise whether they still have active lesions or whether in the absence of obviously active or of visible leprosy lesions they consider themselves cured. Some of the Absentees must be deaths, and people who have moved away, but this number is certainly not large. 'The impression gained is that the desire for treatment generally is so great that very few cases with active lesions would deliberately not come for treatment and pressure of public opinion would also be against this. 'l'wenty-five per cent absentecism seems a high figure, but this is for a full five years, an average of five per cent per year.

(7) Now attending. 'This figure is obtained by deducting the totals of 2 and 4 and 6 from the figure of $\mathrm{I}$, and adding the number of relapses.

(8) Contagious Cases, that is Lepromatous cases who are absentees. This figure represents those actually registered in Out-patient clinics who have ceased to attend. An attempt has been made to bring all Lepromatous cases into the Settlements. More than three-quarters of these cases have actually had treatment in the Settlements for greater or longer periods, but the absentec rate among them all is about 50 per cent. The total number of lepromatous cases that have been registered separately is 250 .

An effort has been made to try and find out why the absentee rate is so high among lepromatous cases. The main reasons seem to be two:I. The effect of treatment is not so dramatic as in the other forms of leprosy and has to be continued for so long that these lepromatous cases become discouraged and therefore stay away.

2. Although social ostracism is not a prominent feature of public opinion in the West Nile, yet because these cases are not pleasant to live with, they tend to become vagabonds, and develop a corresponding mentality which makes them resistant to discipline such as there is in a Settlement and so they absent themselves, and move around constantly making it difficult to trace them.

During this period of five years the two Settlements have continued to operate. The number of patients at Kuluva is now 200 and at Wandi 30. The Settlements have diminished in size because of the availability of Out-patient clinics throughout the District. Most of the patients are either lepromatous cases or those requiring specialized treatment of one kind or another.

The functioning of the scheme has been made possible by the co-operative attitude of the Administration and Chiefs of the District and by the efficiency of medical workers at Dispensaries in keeping the records and administering the dapsone tablets. Dapsone has been used exclusively in the Out-patient's work. Among the medical workers are three leprosy 
assistants who are operating six clinics and the Wandi Settlement. 'I'wo are at the Settlement and one at the southern end of the District. 'This latter Assistant bicycles as much as I 20 miles a weck to visit four clinics. The interest and help given to the scheme by successive District Medical Officers has contributed largely to the measure of success that it has enjoyed.

This report is being published with the permission of the Chief Medical Officer, Ministry of Health, Uganda. 